\title{
Assessment of the early regenerative therapeutic response in graft versus host disease using high definition technology with virtual i-Scan chromoen- doscopy
}
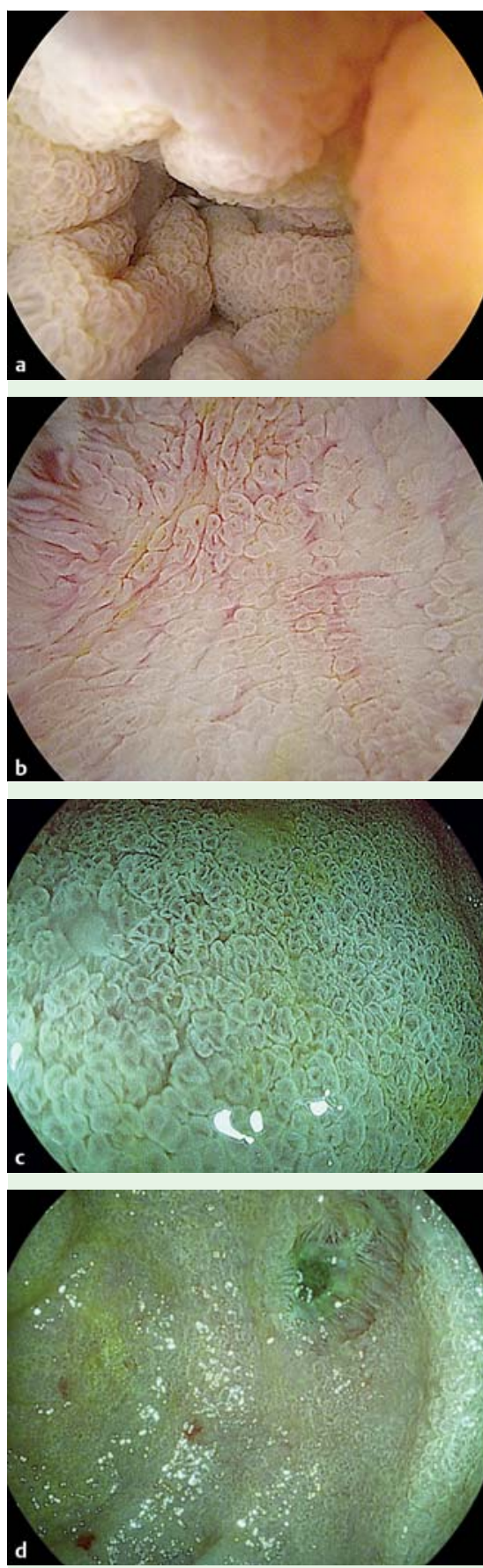

Fig. 1 a, b High definition with i-Scan combination view in a 42-year-old man with a history of allogenic sibling stem cell transplantation. Note the regenerative honeycomb mucosal pattern in the colon. $\mathbf{c}, \mathbf{d}$ High definition with i-Scan virtual chromoendoscopic view again showing the honeycomb, flowery mucosal pattern and healing ulcer.

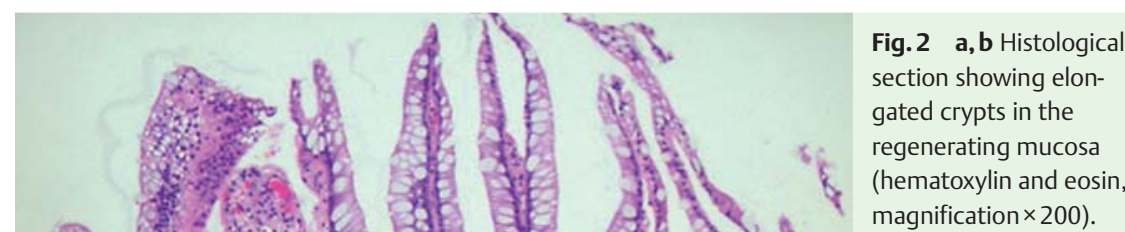
and its involvement is associated with a worse prognosis [1,2]. White light endoscopy findings are nonspecific and often unhelpful in the diagnosis of GvHD and evaluation of its response to therapy. Conventional histological examination of intestinal biopsy samples still represents the gold standard in GvHD diagnosis [3]. Moreover, after allogeneic stem cell transplantation, it could be potentially dangerous to carry out multiple biopsies and may require transfusion of erythrocytes, platelets, or coagulation factors. Here, we describe novel endoscopic findings associated with healing of the colonic mucosa in a patient with GvHD, obtained by high

definition $(\mathrm{HD}+)$ technology with i-Scan virtual chromoendoscopy (Pentax Medical, Tokyo, Japan).

A 42-year-old man, who underwent allogenic sibling stem cell transplantation for chronic lymphocytic leukemia, presented on day 79 with acute symptoms including vomiting, abdominal pain, and diarrhea. Colonoscopy showed multiple ulcers in the left side of the colon. Biopsy specimens were taken and pathological examination revealed colonic GvHD, grade 3/4. The patient was started on high-dose intravenous steroids, followed by antithymocyte globulin (ATG), and - subsequently - extracorporeal photophoresis. Flexible sigmoidoscopy with $\mathrm{HD}+$ and i-Scan virtual chromoendoscopy was carried out to characterize the endoscopic findings of the response to therapy in 
GvHD. A novel endoscopic regenerative honeycomb mucosal healing pattern in GvHD ( $\bullet$ Fig. 1 ) was noted; the pattern characteristically consisted of an exuberant elongated, flowery appearance. The diagnosis was confirmed by histological examination, which demonstrated elongated regenerative crypts in the mucosa (๑ Fig. 2).

HD + with i-Scan endoscopy is an imageprocessing technology that analyzes the endoscopic mucosal and vascular pattern in real time [4]. It has shown promise in differentiating between colonic neoplastic and non-neoplastic lesions, in characterizing mucosal healing in inflammatory bowel disease, and for in vivo diagnosis of duodenal villous atrophy in celiac disease [5]. Here we have reported the novel finding of a honeycomb or flowerlike pattern in the regenerating mucosa using $\mathrm{HD}+$ with i-Scan technology in the assessment of colonic mucosal outcome after therapy for GvHD.

Endoscopy_UCTN_Code_CCL_1AD_2AJ

Competing interests: None
Marietta lacucci ${ }^{1}$, Andrew Daly ${ }^{2}$, Ahsan Chaudhry'2, Peter Duggan², Xianyong Gui ${ }^{3}$, Jonathan Love ${ }^{1}$, Subrata Chosh ${ }^{1}$

${ }^{1}$ Division of Gastroenterology and Hepatology, University of Calgary, Calgary AB, Canada

2 Department of Hematology, Bone Marrow Transplantation Group, Faculty of Medicine, University of Calgary, Calgary AB, Canada

${ }^{3}$ Department of Pathology University of Calgary, Calgary AB, Canada

\section{References}

1 Gratwohl A, Brand R, Apperley J et al. Graftversus-host disease and outcome in HLAidentical sibling transplantations for chronic myeloid leukemia. Blood 2002; 100: 3877 3886

2 Shulman HM, Kleiner D, Lee SJ et al. Histopathologic diagnosis of chronic graft-versus-host disease: National Institutes of Health Consensus Development Project on criteria for clinical trials in chronic graft-versus-host disease: II. Pathology Working Group Report. Biol Blood Marrow Transplant 2006; 12: $31-47$
3 Kreisel W, Dahlberg $M$, Bertz $H$ et al. Endoscopic diagnosis of acute intestinal GVHD following allogeneic hematopoietic SCT: a retrospective analysis in 175 patients. Bone Marrow Transplant 2012; 47: 430-438

4 Kodashima S, Fujishiro M. Novel image-enhanced endoscopy with i-scan technology. World J Gastroenterol 2010; 16: 1043 -1049

5 Cammarota G, Ianiro G, Sparano L et al. Image-enhanced endoscopy with i-Scan technology for the evaluation of duodenal villous patterns. Dig Dis Sci 2013; 58: $1287-$ 1292

\section{Bibliography}

Dol http://dx.doi.org/

10.1055/s-0033-1344823

Endoscopy 2013; 45: E389-E390

(c) Georg Thieme Verlag KG

Stuttgart · New York

ISSN 0013-726X

\section{Corresponding author}

Division of Gastroenterology

Department of Medicine

University of Calgary

Calgary AB

Canada

miacucci@ucalgary.ca 